\title{
Concepção humanista (Carl Rogers): como recurso de atuação na educação para o trânsito - aprendizagem contextualizada.
}

\author{
Silvana Escario*
}

\section{Resumo}

\begin{abstract}
As pesquisas efetuadas no campo da concepção Humanista como estratégia para a atuação docente nos cursos de formação de condutores resultaram neste artigo, que visa explicitar a importância da figura desse profissional como um facilitador ou um agente capaz de promover uma aprendizagem contextualizada e integrativa para os novos condutores, visando à atuação no trânsito. Buscar-se-á evidenciar a importância da contribuição da teoria de Carl Rogers (corrente humanista da Psicologia), como possibilidade de atuação dos professores nos cursos de Formação de Condutores para o Trânsito. Assim sendo, pretende-se estabelecer uma conexão entre os princípios enunciados pelo autor, na esfera da Abordagem Centrada na Educação e no processo de aprendizagem, partindo da proposição de que, através desses princípios, serão alcançados progressos na afinidade pedagógica $e$, consequentemente, na aprendizagem e atuação do aluno no cotidiano do trânsito e na convivência em coletividade. Nesse sentido, defende-se que esta abordagem pode subsidiar uma forma mais interiorizada de responsabilização em relação às possíveis consequências da atuação dos condutores no trânsito, reforçando aspectos como autoavaliação e autodisciplina.
\end{abstract}

Palavras-chave: Psicologia; Educação; Concepção Humanista; Formação de Condutores para o Trânsito. de Condutores para o Trânsito.

\section{A} concepção de Carl Rogers é apresentada como integrante da linha humanista e é reconhecida como a $3^{\mathrm{a}}$ Força da Psicologia devido à sua proposta de entendimento do ser humano. $\mathrm{O}$ autor tem seu trabalho inicialmente desenvolvido na área clínica, com crianças com as quais buscou desenvolver uma teoria sobre a formação da personalidade e conduta, sempre baseada na perspectiva da pessoa. Então, na evolução das suas ideias, Rogers passou do campo exclusivo da Psicoterapia para a aplicação em Grupos, Organizações e na Educação.

Sua proposta de atuação pedagógica coloca o aluno no centro do processo de aprendizagem, produzindo um conhecimento baseado na experiência significativa e tendo na figura do professor o suporte necessário e um facilitador deste processo. A formalização dessa concepção, tão divulgada e utilizada atualmente por Rogers, deu origem

Revista @rquivo Brasileiro de Educação, Belo Horizonte, vol.2, num.3, jan-jun, 2014. * Mestre em educação pela
UNOESC, Docente na UNC
- Universidade do Contesta-
do/Concórdia - SC, nos cur-
sos de Psicologia e Direito. 
à obra Liberdade para aprender, publicada em 1970.

Clarificando ainda mais o tema, Rogers propôs uma educação inovadora, que subvertia a relação de poder da educação tradicional. Nesse processo de aprendizagem, o ensino centra-se no aluno e o professor confia na capacidade de um aprendizado autônomo. A disciplina, antes externa é substituída pela autoavaliação e pela autodisciplina.

A abordagem Rogeriana é estruturalmente humanística e objetiva a aprendizagem de forma "inteira", englobando três focos gerais: cognitivo, atitudinal e procedimental.

Partindo desse pressuposto teórico, objetiva-se, neste artigo, propor uma metodologia educacional voltada para os cursos de Formação de Condutores, baseada na concepção humanista de um professor facilitador, que promova uma aprendizagem contextualizada e integrativa para a atuação dos novos condutores no trânsito.

Nesse sentido, este trabalho é fruto de uma pesquisa bibliográfica, que teve como pano de fundo a obra de Carl Rogers, no âmbito da Abordagem Centrada na Pessoa, aplicada à educação designada por Aprendizagem Centrada no Aluno e, mais especificamente, tendo como foco a atuação dos professores.

Buscar-se-á evidenciar a importância da contribuição desse autor da corrente humanista da Psicologia, como uma possibilidade de atuação dos professores nos cursos de Formação de Condutores para o Trânsito. Assim, o objetivo fundamental será o de tentar estabelecer uma conexão entre os princípios enunciados por Rogers, partindo da conjectura de que estes conduzirão a um progresso na afinidade pedagógica e, consequentemente, no processo de aprendizagem para a atuação do aluno no cotidiano do trânsito. Ao tomar esta posição, temos em mente a afirmação de Rogers de que o Sistema Educativo deverá ter sempre como objetivo o desenvolvimento das pessoas, pois:

\footnotetext{
Neste clima de promoção do crescimento, a aprendizagem tende a ser mais profunda, processar-se mais rapidamente e ser mais penetrante na vida e no comportamento dos alunos do que a aprendizagem realizada na sala de aula tradicional. Isso se dá porque a direção é auto-escolhida, a aprendizagem é autoiniciada e as pessoas estão empenhadas no processo de uma forma global, com sentimentos e paixões tanto quanto com o intelecto. (ROGERS, 1983, p.97)
}

Revista @rquivo Brasileiro de Educação, Belo Horizonte, vol.2, num.3, jan-jun, 2014. 
Concepção humanista (Carl Rogers): como recurso de atuação na educação para o trânsito - aprendizagem contextualizada.

Como aporte teórico, serão apresentados os pressupostos fundamentais do modelo da Abordagem Centrada na Pessoa, assim como os princípios e atitudes aplicados à Educação, que a concepção que Rogers designou por Aprendizagem Centrada no Aluno.

\section{O ENSINO CENTRADO NO ALUNO}

A perspectiva aqui sugerida, como forma de atuação no universo educacional, reporta-se aos princípios básicos do processo terapêutico da abordagem centrada na pessoa, assim como Rogers postula. Tambara e Freire (2007) destacam essas atitudes facilitadoras da mudança terapêutica como sendo: a Consideração Positiva Incondicional, a Compreensão Empática e a Congruência.

\subsection{Aceitação Positiva Incondicional}

Esta se traduz pela aceitação incondicional da pessoa por parte da outra, tal como ela é, e sem juízos de valor ou críticas, a priori (ROGERS, 1985). Dessa forma, o indivíduo pode sentir-se livre para elaborar e reconhecer as suas experiências a partir da sua perspectiva e não a partir da perspectiva do outro, ou seja, a pessoa poderá sentir que não será necessário abdicar das suas convicções para que os outros a aceitem.

A aceitação positiva incondicional é uma atitude firme na crença do potencial interno humano, derivando do principal conceito proposto por Rogers, isto é, a Tendência Atualizante. (GOBBI; MISSEL, 1998).

\subsection{Compreensão empática}

Rogers definiu compreensão empática como uma "capacidade de se imergir no mundo subjetivo do outro e de participar na sua experiência, na extensão em que a comunicação verbal ou não verbal o permite. É a capacidade de se colocar verdadeiramente no lugar do outro, de ver o mundo como ele o vê". (ROGERS; KINGET, 1977, apud GOBBI; MISSEL, 1998, p.45).

Por outras palavras, e entendo que o outro, nesse caso, é aquele

Revista @rquivo Brasileiro de Educação, Belo Horizonte, vol.2, num.3, jan-jun, 2014. 
que faz as aulas de direção, a compreensão empática significa a capacidade que o indivíduo tem, seja ele terapeuta ou professor, de se colocar no lugar do outro. Isso se dará partir das expectativas e vivências do aluno, num processo dinâmico, que não inclui, de forma alguma, uma atitude julgadora. Esse novo posicionamento, por mais simples que possa parecer, produz efeitos na pessoa que a faz sentir-se aceita, compreendida e valorizada em sua globalidade.

\subsection{Congruência}

Finalmente, a congruência pretende indicar o estado de coerência ou acordo interno e de autenticidade de um indivíduo, que se traduz na sua capacidade de aceitar os sentimentos, as atitudes e as experiências, em fim, de ser genuíno e integrado na relação com o outro (ROGERS, 1985).

Essas atitudes propostas pela Terapia Centrada na Pessoa, mais conhecidas como as atitudes facilitadoras (TAMBARA; FREIRE, 2007), se estiverem presentes na relação com o outro, permitirá ao indivíduo participar de um processo de aceitação de si próprio e dos seus sentimentos, tornando-se, por isso, a pessoa que deseja ser. Quem sabe, mais flexível nas suas percepções, buscando objetivos mais realistas, de acordo com a sua capacidade e, consequentemente, tornando-se capaz de aceitar as outras pessoas.

Dessa forma, tais pressupostos foram deslocados para o universo estudantil, pois esse posicionamento busca instigar o professor a preocupar-se, fundamentalmente, em compreender seu aluno e não julgá-lo. Ele terá como foco o processo pedagógico, a importância dos problemas a serem resolvidos e a forma como o aluno os sente. $\mathrm{O}$ mais importante, é que o professor deverá entender que o empenho deve advir da ação do aluno. Portanto, sua atitude será, prioritariamente, a de ser um facilitador.

Ainda considerando o processo de ensino centrado no aluno, temos outro conceito de suma importância postulado por Rogers, isto é, a Tendência Atualizante, na qual o autor entende que esta seria uma visão do homem como sendo um organismo digno de confiança. Para ele:

Revista @rquivo Brasileiro de Educação, Belo Horizonte, vol.2, num.3, jan-jun, 2014. 
A Tendência Atualizante esta presente em todas as ações do indivíduo, pois ela representa o fluxo natural da vida. Ela é o movimento, o processo direcional que caracteriza a própria natureza da vida. Isto é, a presença da Tendência atualizante é que nos permite distinguir um organismo vivo do morto. Isto significa que a tendência atualizante pode ser frustrada, impedida ou desvirtuada, mas não pode ser destruída sem que se destrua também o organismo. (ROGERS, 1983 apud TAMBARA; FREIRE, 2007, p. 49).

Esse conceito, a princípio aplicado ao processo educativo, deve fazer parte da visão do aluno sobre o professor e de sua confiança na capacidade desse profissional de estar em constante atualização. Especificamente, no tema abordado aqui, ressalta-se que a qualidade da relação que se estabelece no contexto pedagógico, frente às atitudes do professor para com o aluno, é um dos fatores que determinam a qualidade da aprendizagem, o desenvolvimento pessoal do aluno e o seu engajamento no estudo.

Para um melhor entendimento didático deste artigo, optou-se por descrever essas atitudes consideradas de suma importância para o processo de aprendizagem do aluno que está participando dos cursos de Formação de Condutores para o Trânsito.

\section{PRINCÍPIOS DA APRENDIZAGEM CENTRADA NO ALUNO}

Rogers abordou, de maneira específica, o assunto aprendizagem em dois livros. O primeiro foi Liberdade para Aprender (1973, $2^{a}$ ed.) e o segundo, Liberdade de Aprender na Nossa Década (1983, $1^{a}$ ed). Nessas obras, ele desenvolve a sua concepção de processo de aprendizagem e propõe uma postura diferenciada do professor, que agora se identifica com o adjetivo de um "facilitador". O centro de suas considerações será, então, a pessoa do aluno, invertendo a órbita de movimentação dos astros.

Nos textos ficam destacados alguns princípios propostos como fundamentais para o processo de aprendizagem: Vejamos:

a) O ser humano contém em si uma potencialidade natural para a aprendizagem (ROGERS, 1986).

Revista @rquivo Brasileiro de Educação, Belo Horizonte, vol.2, num.3, jan-jun, 2014. 


\section{Silvana Escario}

b) A maioria das aprendizagens significativas é adquirida pela pessoa em ação, ou seja, pela sua experiência (ROGERS, 1986).

c) A aprendizagem concretiza-se de forma plena quando o professor é autêntico na relação pedagógica (ROGERS, 1986).

d) Para uma aprendizagem adequada torna-se necessário que o aluno aprenda a aprender, quer dizer que, para além da importância dos conteúdos, o mais significativo para Rogers é a capacidade do indivíduo interiorizar o processo constante de aprendizagem (ROGERS, 1986).

e) A aprendizagem significativa acontece quando o assunto é percebido pelo aluno como relevante para os seus propósitos, o que significa que o aluno aprende aquilo que percebe como importante para si (ROGERS, 1974).

f) Não podemos ensinar, apenas podemos facilitar a aprendizagem (ROGERS, 1974).

g) A aprendizagem que implique uma mudança ameaçadora na percepção do self tende para a resistência (ROGERS, 1974).

h) As aprendizagens são melhor apreendidas e assimiladas quando a ameaça externa ao self é reduzida ao mínimo (ROGERS, 1974).

i) A aprendizagem qualitativa acontece quando o aluno participa responsavelmente nesse processo (ROGERS, 1974).

j) A aprendizagem que envolve a autoiniciativa por parte do aluno e a pessoa na sua totalidade, ou seja, as dimensões afetivas e intelectuais tornam-se mais duradouras e sólidas (Ibidem).

k) Quando a autocrítica e a autoavaliação são facilitadas, e a avaliação de outrem se torna secundária, a independência, a criatividade e a autorrealização do aluno tornam-se possíveis (ROGERS, 1974).

Numa perspectiva mais evoluída do processo de aprendizagem, o autor propõe, além de princípios norteadores de uma prática diária, um grupo de qualidades básicas para transformar um professor em um

Revista @rquivo Brasileiro de Educação, Belo Horizonte, vol.2, num.3, jan-jun, 2014. 
Concepção humanista (Carl Rogers): como recurso de atuação na educação para o trânsito - aprendizagem contextualizada.

facilitador do processo de aprendizagem.

A qualidade primordial refere-se à "Autenticidade" do facilitador, sendo esta a qualidade elementar que vislumbra a capacidade do facilitador de ser real, sem máscaras na relação com o aluno (ROGERS, 1986).

Na sequência, mas não menos importante, temos a qualidade da "Aceitação e Confiança", que se anuncia na atitude e capacidade de aceitar a pessoa do aluno, com os seus sentimentos, opiniões, valores e, essencialmente, na confiança nesse indivíduo, pois:

Se os professores aceitam os alunos como eles são, permitem que expressem seus sentimentos e atitudes sem condenação ou julgamentos, planejam atividades de aprendizagem com eles e não para eles, criam uma atmosfera de sala de aula relativamente livre de tensões e pressões emocionais, as consequências que se seguem são diferentes daquelas observadas em situações onde essas condições não existem. As consequências, de acordo com as evidências atuais, parecem ser na direção de objetivos democráticos (ROGERS apud GOBBI; MISSEL, 1998, p.27).

Por fim, temos a capacidade "Compreender Empaticamente" o aluno, ou seja, compreendê-lo a partir da sua concepção de mundo. Esta concepção acontece "Quando o professor tem a capacidade de compreender internamente as reações do estudante, tem uma consciência sensível da maneira pela qual o processo de educação e aprendizagem se apresenta ao estudante" (ROGERS, 1986, p.131), o facilitador, vivencia esse processo "como se" fosse o aluno, mas sem o sê-lo efetivamente, promovendo, dessa forma, uma aprendizagem significativa e interiorizada.

\section{INTERFACE: CONCEPÇÃO HUMANISTA NOS CURSOS DE FORMAÇÃO DE CONDUTORES}

A partir do novo Código de Trânsito Brasileiro, deu-se um passo significativo considerando a formação do condutor. Este passo configurase na obrigatoriedade de frequência em um curso teórico que fez com que o candidato tivesse acesso às informações que são relevantes para a futura conduta no trânsito.

Não é possível ignorar que o aluno candidato à primeira

Revista @rquivo Brasileiro de Educação, Belo Horizonte, vol.2, num.3, jan-jun, 2014. 
habilitação já carrega consigo uma história referente ao trânsito. A partir do momento em que ele vai para a sala de aula, passa a ter acesso a novas informações e outros aperfeiçoamentos. Dessa forma, é nesse momento que a concepção Humanista de ensino e aprendizagem pode ser aplicada como estratégia de atuação em sala de aula, pois experiências docentes, nas quais as aulas são desenvolvidas a partir dessa concepção, podem ser um referencial prático de funcionamento. É necessário que o condutor orquestre e respeite os direitos dos outros, tenha dignidade humana, conheça a legislação, pense no bem comum e dê prioridade à vida, em qualquer circunstância. Assim, observa-se que a formação de um condutor consciente e comprometido com a vida, não depende exclusivamente dos conteúdos previstos na Resolução 050/98, do Código de Trânsito Brasileiro, mas sim, do processo pedagógico, ou seja, da forma como os conteúdos são desenvolvidos, baseados nos princípios de base humanista em que o compromisso individual é assumido e a convivência social, ética e a prática da cidadania são reforçados.

A Educação para o trânsito, como já dissemos, é um
aspecto a mais da educação ético-social, entendida
como um conjunto de valores, normas, princípios,
hábitos, que determina e ajuda a possibilitar a
convivência social entre as pessoas, mas com conteúdo
próprio. Na realidade, é um aspecto atual enquadrado
nas ciências sociais e que engloba temas relativos
ao desenvolvimento econômico e sociocultural das
sociedades avançadas, ao estudo do meio ambiente
e seus problemas ou da evolução tecnológica e suas
consequências sociais. (HOFFMANN; CRUZ; ALCHIERI,
2003, p.109).

A educação para o trânsito está conectada à educação social e moral da pessoa, pois a forma com que o indivíduo se apresenta no trânsito, nas suas relações, como resolve seus conflitos, seus hábitos e princípios serão revelados pela sua conduta. Ainda para fortalecer esse posicionamento, reporta-se a Hoffmann, Cruz e Alchieri (2003, p.175), que afirmam ser o trânsito um fenômeno social complexo, no qual acontece uma diversidade de variáveis, todas ao mesmo tempo. 0 homem, o meio ambiente e as necessidades diferenciadas influenciam no comportamento das pessoas que, de alguma forma, se expressa no trânsito.

Temos, ainda, Vasconcellos (1998), que nos diz que o trânsito é feito de pessoas, dentro de uma determinada sociedade com grandes diferenças sociais e políticas e com interesses diversos. É necessário 
Concepção humanista (Carl Rogers): como recurso de atuação na educação para o trânsito - aprendizagem contextualizada.

localizar este indivíduo dentro da sociedade da qual ele faz parte, para que ele conheça os princípios de cidadania e se inclua como cidadão. Segundo o autor, "o homem no trânsito não pode ser encarado como categoria abstrata, como 'o gênero humano': o homem é antes de tudo, um ser político e social, que tem história, personalidade, interesses" (VASCONCELLOS, 1998, p.65).

Trabalhar educação para o trânsito sem trabalhar o homem e suas relações sociais fazendo um resgate à cidadania, a fim de desencadear uma cultura de respeito aos direitos e deveres e a participação de fato do cidadão, é como trabalhar numa base sem pilares que a sustentem. É fundamental que se trabalhe o indivíduo na educação para o trânsito a partir das diferenças individuais, dos grupos, dos relacionamentos interpessoais, enfim, do cidadão como um indivíduo consciente do seu papel na sociedade. Trabalhar a socialização de um modo geral, fomentando o amor à vida, a solidariedade, o respeito e a cooperação, na busca uma convivência harmônica e de uma a prática de valores que o proteja.

Então, se propõe uma educação para o trânsito no âmbito de uma educação para a socialização, uma vez que:

A educação para o trânsito é mais um capítulo da educação ético-social que não tem sentido como disciplina de conteúdo independente. Seu conhecimento teórico e prático se enquadra nos conhecimentos organizados sistematicamente nas duas grandes áreas das ciências sociais e ciências naturais, uma vez que integra o ambiente e a realidade social e, assim o contexto em que vive o aluno [...] (HOFFMANN; CRUZ; ALCHIERI, 2003, p. 106-107).

Pode-se concluir que a educação para o trânsito deriva da educação social ou moral e isso nos leva à necessidade de se trabalhar o indivíduo, o seu papel na sociedade e suas relações com as pessoas e o com o meio ambiente. Integra-lo à sociedade significa que ele deverá estar presente, de forma efetiva, possibilitando a incorporação de hábitos e atitudes que sejam benéficas à coletividade. Isso permite um resgate dos princípios éticos somados à educação voltada para o ser, o que contribui para a formação de um cidadão.

Permitir ao indivíduo experimentar situações de convivência que acontecem frequentemente no trânsito, partindo do contexto no qual ele está inserido socialmente, propicia a percepção de como a socialização

Revista @rquivo Brasileiro de Educação, Belo Horizonte, vol.2, num.3, jan-jun, 2014. 


\title{
Silvana Escario
}

é fundamental. Ele faz parte de uma sociedade, portanto, têm direitos e deveres comuns a esse grupo. Desse modo, o sistema trânsito pode funcionar melhor se o condutor de automóvel tiver consciência de sua responsabilidade.

\begin{abstract}
A educação para o trânsito deverá ser adaptada aos diferentes níveis e ciclos da evolução das capacidades de compreensão do mundo social, seguindo as orientações dos princípios da psicologia do desenvolvimento, da aprendizagem e das disciplinas das ciências sociais [...] (HOFFMANN; CRUZ; ALCHIERI, 2003, p. 113).
\end{abstract}

Assim, propõe-se que, nos trabalhos desenvolvidos para a educação para o trânsito, o método ou técnica utilizada deve contemplar a capacidade de compreensão do aluno em relação ao mundo social, tornando possível a ele relacionar os ensinamentos trabalhados à vivência social.

\section{CONCLUSÃO}

Considerando Parlett e Hamilton (1982), o meio de aprendizagem representa um complexo de variáveis culturais, sociais, institucionais e psicológicas. A interação dessas variáveis vai definir, de forma diferenciada, o que acontece em sala de aula. É fundamental que se considere este complexo de variáveis se quisermos de fato trabalhar com o meio de aprendizagem real, aberto, no qual professor e aluno participam.

Através do meio de aprendizagem, irá ocorrer a relação didática, sendo ela o elemento base da dinâmica de uma aula. O meio de aprendizagem e relação didática se confundem, pois ambos acontecendo ao mesmo tempo. Sendo assim, ensinar requer, de acordo com esse modelo, um nível de maturidade e segurança por parte do professor, que Ihe permita, por um lado, diminuir a assimetria do seu poder enquanto docente, partilhando a responsabilidade do processo de aprendizagem e, por outro, acreditar na capacidade do aluno de aprender e de pensar com autonomia.

Por tudo o que foi referido, aprender é um processo dinâmico, que exige concentração, interesse, empenho e motivação. Por tais razões, é

Revista @rquivo Brasileiro de Educação, Belo Horizonte, vol.2, num.3, jan-jun, 2014. 
Concepção humanista (Carl Rogers): como recurso de atuação na educação para o trânsito - aprendizagem contextualizada.

importante que as relações de cooperação e participação entre professor e alunos estejam presentes.

De acordo com essa abordagem, o aluno passa a ter uma participação ativa e interventiva no curso de formação de condutores, tornando-se um corresponsável no processo. O que não significa que o professor abdique da sua responsabilidade. A classe poderá transformar-se num grupo interativo, no qual a figura do docente deixa de ter centralidade. Assim, perde-se a representação de um agregado de indivíduos que estão lado a lado, sem direito a se comunicar, para surgir a um organismo vivo, em que todos os membros mantêm relações entre si.

Mas, não basta enunciar esses princípios que, à primeira vista, nos soam harmoniosos. É necessário pô-los em execução, o que não deixa de exigir um esforço permanente por parte de quem educa. Nas palavras de Rogers:

Uma abordagem desse tipo, centrada na pessoa, é uma filosofia que se acha em consonância com os valores, os objetivos e os ideais que historicamente constituíram o espírito da nossa democracia. [...] Ser plenamente humano, confiar nas pessoas, conceder liberdade com responsabilidade não são coisas fáceis de atingir. $O$ caminho que apresentamos constitui um desafio. Envolve mudanças em nosso modo de pensar, em nossa maneira de ser, em nossos relacionamentos com os estudantes. Envolve uma dedicação difícil a um ideal democrático. (ROGERS, 1986, 326-327).

Nesse sentido, objetiva-se educar condutores de automóveis para a cidadania, partindo da concepção humanista de atuação do professor em sala de aula.

\begin{abstract}
Humanistic Approach (Carl Rogers): Using it as a resource in traffic education programs - Contextualized Learning

The present article was originated from a research that aims at explaining the use of the Humanistic Approach as a teaching strategy in driving courses where a teacher is present and promotes contextualized and integrating teaching techniques to these new conductors. The importance of Carl Rogers' (Humanistic Approach) contribution was analyzed as a teaching possibility in driving courses in Brazil. The aim was to establish a connection between Carl Roger's Humanistic Approach and the student-centered approach and the learning process, starting from the proposition that these principles will govern psychological affinity and consequently in the learning process. This
\end{abstract}

Revista @rquivo Brasileiro de Educação, Belo Horizonte, vol.2, num.3, jan-jun, 2014. 


\section{Silvana Escario}

approach could also affect the every-day performance when driving of this student in our society. We defend that that this approach can support and students to internalize responsibility and possible consequences of their acts as drivers - strengthening aspects such as self-evaluation and self-discipline.

Key words: Psychology; Education; Humanist Approach; Driving courses.

\section{RESUMEN}

Visión humanista (Carl Rogers): como recurso de actuación en la educación para el tránsito - un aprendizaje contextualizado

De acuerdo con las investigaciones hechas fue posible llegar al presente estudio que tuvo por objetivo aclarar sobre la utilización de la Concepción Humanista como estrategia de actuación docente, en los cursos de formación de conductor en el cual, la figura del profesor es ser un facilitador que promueve un aprendizaje contextualizado e integrativo de la actuación en el tránsito de estos nuevos conductores. Luego, se buscó evidenciar la importancia de la contribución de Carl Rogers (corriente humanista de la Psicología), como una posibilidad de actuación de los profesores en los cursos de Formación de Conductores para el Tránsito. Entonces se establece una conexión entre los principios enunciados por Carl Rogers, en la esfera del Abordaje Centrado para la Educación y el proceso de aprendizaje, partiendo de la proposición de que estos gobernarán un progreso en la afinidad pedagógica y consecuentemente en el proceso de aprendizaje y actuación del alumno en el cotidiano del tránsito en nuestra colectividad. Pues, se defiende que este abordaje puede subsidiar una forma más interiorizada de responsabilización, posibles consecuencias sobre la actuación de los conductores en el tránsito - reforzando aspectos como auto evaluación y auto disciplina.

Palabras-llave: Psicología. Educación. Concepción Humanista. Formación de Conductores para el Tránsito.

\section{REFERÊNCIAS}

GOBBI, Sérgio Leonardo, MISSEL, Sinara Tozzi (Org.) Abordagem Centrada na Pessoa: vocabulário e noções básicas. Editora Universitária UNISUL, 1998.

HOFFMANN, Maria Helena; CRUZ, Roberto Moraes; ALCHIERI, João Carlos. Comportamento Humano no Trânsito. São Paulo: Casa do Psicólogo, 2003.

PARLETT. M; HAMILTON, D. Avaliação iluminativa: uma nova abordagem no estudo de programas inovadores. In GOLDBERG, M. A; SOUZA, C. P. Avaliações educacionais e vicissitudes, controvérsias e desafios. São Paulo: EPU, 1982.

ROGERS, Carl. A Terapia Centrada no Paciente. Lisboa: Moraes Editores, 1974.

ROGERS, Carl. Tornar-se Pessoa. $7^{a}$ ed. Lisboa: Moraes Editores, 1985.

Revista @rquivo Brasileiro de Educação, Belo Horizonte, vol.2, num.3, jan-jun, 2014. 
Concepção humanista (Carl Rogers): como recurso de atuação na educação para o trânsito - aprendizagem contextualizada.

ROGERS, Carl. Liberdade para Aprender, $2^{\mathrm{a}}$ ed. Belo Horizonte: Inter Livros de Minas Gerais, 1973.

ROGERS, Carl. Liberdade de Aprender em Nossa Década, $2^{a}$ ed. Porto Alegre: Artes Médicas, 1986.

ROGERS, Carl. Um Jeito de Ser, $3^{a}$ ed. S. Paulo: Editora Pedagógica e Universitária, 1983.

TAMBARA, Newton; FREIRE, Elizabeth. Terapia Centrada no Cliente: teoria e prática - um caminho sem volta. Porto Alegre: Delphos, 2007, 192 p.

VASCONCELOS, Eduardo A. O que é Trânsito. São Paulo: Brasiliense, 1998. 